\title{
La conservación del patrimonio etnográfico a través de la musealización
}

\author{
Blanca Flor Herrero Morán
}

\begin{abstract}
Resumen: La conservación del patrimonio etnográfico está muy ligada al proceso de musealización que se está llevando a cabo a nivel mundial desde hace varias décadas. El patrimonio etnográfico, antes calificado viejo y considerado como algo inútil, ahora es denominado antiguo, se conserva, colecciona y revaloriza pasando a ser un bien museable. El patrimonio etnográfico es la mejor y más perfecta conjunción entre patrimonio tangible e intangible, y por ello el interés de los museos etnográficos no debe residir sólo en conservar, coleccionar, exhibir y proyectar el objeto (con un carácter únicamente materialista) sino también el no objeto (piezas inmateriales e ideas que contextualizan los bienes) y los sujetos (aludiendo a la comunidad). A su vez, los museos deben custodiar el patrimonio etnográfico teniendo en cuenta las condiciones medioambientales para su óptima conservación.
\end{abstract}

Palabras clave: conservación, patrimonio etnográfico, musealización, museo etnográfico.

\section{Conservação do património etnográfico através de musealização}

Resumo: A conservação do património etnográfico está intimamente ligada ao processo de musealização que se tem vindo a levar a cabo a nível mundial, desde há várias décadas. O património etnográfico, antes qualificado como velho e considerado como algo inútil, é agora denominado de antigo, sendo conservado, coleccionado e revalorizado e passou a ser um bem museológico. O património etnográfico é a melhor e a mais perfeita combinação de património tangível e intangível e, portanto, o interesse dos museus etnográficos não deve residir apenas em conservar, coleccionar, exibir e projetar o objeto (com um carácter, únicamente materialista), mas também o não-objeto (partes imateriais e ideias que contextualizam os bens) e os sujeitos (aludindo à comunidade). Por sua vez, os museus devem guardar o património etnográfico, considerando as condições ambientais para a sua preservação ideal.

Palavras-chave: conservação, património etnográfico, museológico, museu etnográfico.

\section{Ethnographic heritage conservation through musealization}

\begin{abstract}
The conservation of ethnographic heritage is closely linked to the musealization process that is taking place in the world for several decades. The ethnographic heritage, before qualified as old and considered as useless, currently it is called ancient, it is preserved, collected and revalued to become a museum piece. The ethnographic heritage is the best and the most perfect conjunction between tangible and intangible heritage and thus the interest of ethnographic museums must not reside only in the preservation, collection, exhibition and projection of the object (its materialistic character, merely) but also on the non-object (immaterial parts and ideas that contextualize the assets) and the subjects (referring to the community). At the same time, museums must guard the ethnographic heritage taking into account the environmental conditions for its optimal conservation.
\end{abstract}

Key words: conservation, ethnographic heritage, museology, ethnographic museum.

La historia del arte nos muestra, con innumerables ejemplos, el poco aprecio que en determinados momentos se ha tenido por las obras de culturas anteriores que no se han querido y/o podido conservar. Tras la revolución industrial se impone la democratización del acceso a la cultura y se aumenta la conciencia y la conservación patrimonial. Ahora bien, llama la atención que, en ese 
momento, el patrimonio industrial y el patrimonio etnográfico fueran relegados prácticamente al olvido y su conservación quedara en un segundo plano.

La conservación del patrimonio etnográfico está relacionada con el coleccionismo y la musealización. El coleccionismo es un proceso que genera corrientes afectivas hacia las piezas que se adquieren y se basa en los valores que los bienes coleccionados poseen o se les atribuyen. Luego estos valores son heredados por los museos quienes hacen una actualización y revalorización de los mismos. Cuando se colecciona y musealiza el patrimonio etnográfico material e inmaterial se le da una serie de valores sobreañadidos que modifica los valores originales de los bienes gracias a las diferentes funciones y a la conjunción del objeto-no objeto-sujeto que se llevan a cabo dentro de los museos.

\section{Proceso de conservación del patrimonio etnográfico}

En un primer momento la gente poseedora de patrimonio etnográfico mostró recelo y rechazo hacia el progreso y los avances producidos por la industrialización y decidieron conservarlo pero, poco después, se entregaron totalmente al progreso. Es más, apoyados en la idea de un cambio de vida de mayor nivel económico, comenzaron a reformar y cambiar la vivienda y los enseres tradicionales y a desembarazarse de baratijas precarias, anticuadas e innecesarias que les estorbaban y ocupaban espacio. Este cambio de mentalidad favoreció el expolio de piezas etnográficas en el medio rural, un proceso gradual en el que cada vez participaron más personas y más piezas.

Durante un largo periodo hubo una fase de desprecio y reproche hacia los denominados "objetos etnográficos". La máquina (debido a la industrialización) había desplazado a la persona (el artesano). Las piezas dejaban de hacerse a mano y los productos fabricados en la cinta transportadora influían decisivamente en el gusto. La variación continua de los enseres modernos, posibilitada por la proliferación de materiales, formas, decoraciones y técnicas que, unidos a la producción seriada, aceleran el proceso de envejecimiento de los objetos demandados por la sociedad, o impuestos a ella por la publicidad y la técnica industrial, es la esencia de la pérdida de valor de los bienes etnográficos por parte de sus propietarios que empiezan a intercambiarlos, venderlos y malvenderlos. Ya lo dijo Gombrich: "Debemos advertir que cada adelanto o progreso en una dirección entraña una pérdida en otra" (Gombrich 2003: 9).

A la fase de permuta o cambio de objetos nuevos por objetos usados, le sucedió la de compraventa. Los chamarileros empezaron a recorrer diversos pueblos con el fin de recopilar, mayoritariamente a través de la compra, los objetos usados más atractivos o más bellos para luego venderlos en rastros, mercadillos y, a título personal, a anticuarios, a coleccionistas y a museos. Con esta actitud, durante varias décadas, los chatarreros y algunos anticuarios procedentes de la ciudad, arrasaron con el patrimonio etnográfico con fórmulas a menudo poco ortodoxas y fraudulentas y contribuyeron a la dispersión masiva del mismo a través de mercados regionales, nacionales e internacionales. Las consecuencias de esta práctica expoliadora fueron nefastas para la conservación del patrimonio etnográfico. No obstante, aunque en muchas ocasiones no fueran conscientes de ello, con la compra-venta del patrimonio etnográfico también se favoreció su difusión y conservación ya que probablemente numerosos objetos habrían sido destruidos, sin duda por ignorancia. 
En este mismo momento, de forma paulatina, las piezas etnográficas empiezan a llamar la atención a diferentes personas y personalidades que se sensibilizaron y vieron en ellas un valor no sólo estético (forma, función y decoración) sino también histórico y cultural (documentos del pasado, de la tradición y la identidad). Surge entonces el coleccionista de objetos etnográficos que se interesa por estas piezas, toma un contacto cada vez más estrecho con ellas y se convierte en un especialista en la materia. La labor del coleccionista etnográfico centrado en un primer momento en la compra del mayor número de piezas posible evita y/o palia la dispersión atomizada de las piezas por diferentes países (bien en instituciones museísticas bien en domicilios particulares).

Después, gracias a la revalorización del objeto etnográfico surgida en el medio urbano, al coleccionismo etnográfico y a la difusión de los medios de comunicación, los poseedores de objetos etnográficos se dan cuenta de su valor económico y sentimental y deciden no malvender ni desprenderse de todas las piezas haciendo una selección de las mismas para conservarlas y legarlas a sus descendientes.

En las últimas décadas se ha perdido en torno al $90 \%$ del patrimonio etnográfico, desapareciendo así miles de utensilios, enseres y aperos artesanales enterrados bajo los escombros de las casas, olvidados en los desvanes o vendidos a anticuarios a precios de ganga que luego los comercializan a precio de oro.

La situación no es nueva, ya que desde mediados de los sesenta se ha producido, en el ámbito artístico en general y en el de la etnografía en particular, un intercambio desigual basado en el escaso valor otorgado a las piezas, que prácticamente eran regaladas a los anticuarios e intermediarios, porque estorbaban. Este hecho no es aislado, se ha producido en casi todas las partes del mundo. Incluso, en determinadas zonas africanas sigue ocurriendo. Dicha idea ya fue apuntada por Panofsky hace tres décadas:

"Todos nosotros hemos visto con nuestros propios ojos cómo se trasladaban los fetiches y los utensilios de las tribus africanas desde los museos etnológicos a las exposiciones artísticas" (Panofsky 1985: 29).

Señala Eloísa Wattenberg "el patrimonio etnográfico se ve cada vez más indefenso ante su abandono, el alarmante expolio de que es objeto y la degradación que paulatinamente experimenta en lo que de él se mantiene vivo" 'Wattenberg 1995: 519). Este mismo aspecto lo recoge José Luis Alonso Ponga incidiendo en la complejidad que conlleva la conservación y puesta en valor del patrimonio etnográfico pues:

"Era muy frecuente que, en las sociedades en proceso de cambio, los objetos etnográficos desaparezcan del grupo que los ha producido y con ellos los procesos de producción y no pocos testimonios de vida. Sin, embargo, en algunos casos en estos estados liminales, la sociedad toma conciencia del valor simbólico de los mismos, lo que mueve al grupo a su salvaguarda, no tanto por el valor de uso que tengan, como porque quedan como testimonio de la propia sociedad que comienza a desaparecer. Se opera aquí un proceso reduccionista mediante el cual, puesto que no se pueden guardar todos los objetos, se decide cuáles se conservan y cuáles se abandonan definitivamente. Es todo un proceso complejo donde la toma de decisiones es muy importante. En este proceso de resemantización se altera el valor de mercado, ya que el objeto pasa de una fase en la que no se le reconoce ningún valor a otra en la se sobrevalora por la escasez de ejemplares" (Ponga 2002: 157). 
En este sentido, teniendo en cuenta la dificultad de valorar y conservar lo cotidiano, Olaia Fontal afirma:

"En nuestras casas hay numerosos objetos con los que crecemos y a los que estamos habituados porque siempre los hemos visto: utensilios, ropa, muebles, fotografías, documentos... Eso no significa necesariamente que lo valoremos. De hecho, casi todos nosotros nos hemos encontrado en algún cajón un objeto cuya forma tal vez identificamos pero del que no sabemos absolutamente nada, salvo que alguien de nuestra familia, por algún motivo desconocido, lo guarda en ese cajón. (...) Sabemos que los objetos existen porque alguien los construye, pero también porque alguien decide conservarlos" (Fontal 2003: 285).

\section{Proceso de musealización del patrimonio etnográfico}

Puesto que el coleccionismo no tiene límites, todo es coleccionable (desde lo más importante a lo intrascendente), y no existen unas normas genéricas; lo primero que hay que valorar es el hecho de que en numerosos países desarrollados, entre los que se incluyen España y Portugal, a partir del último tercio del siglo XX se empiecen a conservar, recopilar y adquirir piezas etnográficas de forma sistemática tanto por parte de instituciones públicas y privadas como por personas a título individual.

La labor de recogida de piezas etnográficas es admirable no sólo por su carácter insustituible sino también por su carácter irrecuperable de tal modo que si no se hubieran empezado a adquirir estas piezas en el momento preciso, hoy, gran parte del patrimonio etnográfico no habría sobrevivido y por lo tanto no lo habríamos conocido.

De esto se deduce que el coleccionista de patrimonio etnográfico (tanto en su variante material como inmaterial) se convierte en un auténtico configurador de patrimonio, del que se hace responsable desde que lo adquiere como medida de protección y conservación ante el inminente peligro de desaparición de muchas de las piezas adquiridas. El coleccionista toma conciencia patrimonial de una serie de piezas que durante demasiado tiempo han sido desechadas del concepto de patrimonio por su carácter funcional y cotidiano, poniendo en valor piezas que son testimonio y documento de una época y una forma de entender la vida. Esta tarea es bastante compleja pues no se trata de adquirir y reunir una serie de piezas sino de delimitar cuándo se trata de una pieza con valor etnográfico y cuándo es un simple objeto en desuso, dos criterios que no siempre se suelen tener claros. De ahí la dificultad de formar una colección que sea verdaderamente una pionera recopilación museística de patrimonio etnográfico.

Las piezas que se exhiben en los museos etnográficos no son patrimonio exclusivo del museo, pues en muchas casas hay piezas similares (aparatos en desuso, objetos del pasado, recuerdos familiares, enseres y artefactos diversos...). El patrimonio etnográfico no fue creado para ser musealizado $y$, sin embargo, el museo se ha convertido en un buen destino para este tipo de bienes que tienen una entidad socio-cultural. Si nos preguntamos por qué el patrimonio etnográfico es merecedor de estar en un museo, la respuesta es sencilla: porque es el reflejo de la cultura que representa, y los bienes etnográficos no dejan de tener un sentido testimonial e ilustrativo de la diversidad cultural, además del sentido utilitarista, por cuanto cada objeto suele tener una función y ha sido construido para realizar una tarea. 
El último tercio del siglo XIX es un periodo esencial desde el punto de vista museológico en general, y de la museología etnográfica en particular, por dos razones: por un lado, se multiplican los museos de todas las disciplinas en Europa y Norteamérica y, por otro, la etnología se convierte en un gran campo de estudio como consecuencia tanto de la expansión colonial europea como de la necesidad de salvaguardar las diferentes culturas tradicionales europeas que la revolución industrial había empezado a destruir. Paulatinamente la etnología y la antropología dejan de ser secciones de los Museos de Historia Natural y conquistan un espacio propio que pasará de ser concebido como gabinete de curiosidades y/o cámara de las maravillas a funcionar como un auténtico museo.

Reflejo de la importancia que se le ha ido otorgando de forma progresiva al patrimonio etnográfico, han proliferado numerosas instituciones museísticas diseminadas por todo el mundo que han facilitado y favorecido su conservación. Por ello, los museos etnográficos cobran ahora una especial atención ante el riesgo de desaparición y conservación del patrimonio etnográfico.

El museo etnográfico, una tipología que parte de la conjunción de la museología de la idea y del objeto, se ha denominado con multitud de apelativos que no tienen por qué ser sinónimos: museo del hombre, museo de las ciencias del hombre, museo de etnología, museo de arte popular, museo del pueblo, museo de artes y oficios tradicionales, museo de costumbres y tradiciones, museo de artes y tradiciones populares, museo de la vida y las costumbres tradicionales, museo del folklore, ecomuseo, museo de la memoria, museo de la civilización, museo étnico, museo etnológico, museo de identidad, museo de antropología, etc.

Dentro de la diversidad de tipologías museísticas existentes, los museos de etnografía tienen una gran complejidad ante la amplitud etnográfica actual. Tal y como afirma Iñaki Díaz Balerdi, "la desbocada fiebre de creación de nuevos museos encuentra su ejemplificación en lo acaecido con el llamado patrimonio etnográfico puesto que, hoy en día, cualquier geografía se ve trufada de un sinfín de museos que recogen las peculiaridades de determinados grupos humanos y de sus formas de vida" (Díaz 2008: 65). Por este motivo, los museos etnográficos resultan polémicos en función del papel que tienen que desempeñar pues algunos de los denominados museos etnográficos son, como dice Concha Casado: "el desván de la abuela". Pero, aunque hay muchos "desvanes de la abuela" (habitaciones, locales y casas donde se colocan y acumulan un montón de objetos) y colecciones etnográficas, son pocos los museos etnográficos verdaderos que cumplen las funciones asignadas por definición de ICOMOS a toda institución museística.

Ahora bien, la importancia no radica sólo en la introducción del patrimonio en el museo con el fin de conservarlo o en la creación de numerosos museos etnográficos sino en la puesta en marcha y funcionamiento de los mismos. Por ejemplo, conviene evitar que los museos etnográficos se conviertan en desvanes de la abuela o en mausoleos llenos de objetos polvorientos, de interés casi exclusivamente para expertos, caros de mantener y difíciles de renovar. Porque no es lo mismo un museo de bienes tradicionales que un museo tradicional o anclado en la museología tradicional.

\section{Museos etnográficos: objeto, no objeto y sujeto}

En esencia se trata de pasar del objeto de museo al objeto del museo. Tener un buen proyecto museológico y una metodología adecuada son las claves para que un museo no sea un simple contenedor o escaparate de objetos sino una institución en la que sus piezas transmitan ideas y trasciendan la condición material de tal manera que sea un museo del objeto, del no objeto y del 
sujeto. La principal tarea de estos museos no es la contextualización del arte sino la contextualización de las ideas culturales y sociales que el patrimonio etnográfico posee ya que coadyuva a explicar costumbres, creencias, pensamientos, tradiciones... Para Gombrich lo material y lo inmaterial están irremediablemente unidos:

"Las costumbres, los oficios y, por supuesto, las leyendas y creencias comunes a la tribu van íntimamente unidos al lenguaje y a las formas del pensamiento de cualquier civilización" (Gombrich 2004: 75).

Se trata de una relación recíproca pues el objeto contribuye a configurar el contexto y, a su vez, el contexto dota de pleno significado al objeto. Por ello, algunos problemas graves en los museos son el ingreso de objetos descontextualizados -de ahí la importancia de la documentación, la catalogación y la investigación-, la pérdida del valor contextual de una pieza al introducirla en un museo, la falta de un discurso lógico que permita un mejor y mayor conocimiento y reconocimiento de los fondos, la ausencia de actividades interdisciplinares...

En los museos etnográficos, la colectividad está por encima de la individualidad de una pieza o un autor como puede ocurrir en los museos de Bellas Artes. Un objeto aislado ofrece una muestra empobrecedora para su valoración cultural corriendo el peligro de caer en el fetichismo, mientras que lo verdaderamente importante es establecer relaciones entre el objeto con otros objetos y entre el objeto y el sujeto. Para ello es necesario observar y analizar críticamente los objetos que forman parte de un conjunto ordenado y un contexto colectivo de recursos materiales y técnicos (sirva de ejemplo las grabaciones sonoras y audiovisuales de las voces de los testigos vivos que utilizaron y convivieron con los objetos etnográficos).

Los museos etnográficos deben hacer algo para explicar no sólo los objetos que albergan sino también la vida y la cultura que hay tras las piezas. En el pasado esa cultura era conservada, transmitida y absorbida en gran medida en casa y en la calle pero ahora hay que conservar la existencia y la esencia del patrimonio etnográfico evitando que los objetos caigan en el desconocimiento y sean objetos desconocidos e intentando que formen parte de nuestra memoria por lo que el museo debe potenciar su conservación, conocimiento y reconocimiento (hay que conservarlos, conocerlos, entenderlos, valorarlos y apreciarlos).

El patrimonio etnográfico, entendido tanto en su variante material (objeto) como inmaterial (no objeto) tiene muy presente al ser humano (sujeto); de tal manera que la musealización del patrimonio etnográfico ha posibilitado la unión objeto-no objeto-sujeto pues los bienes culturales etnográficos constituyen un Patrimonio que debemos conservar, conocer, cuidar, valorar, proteger y difundir. El objeto etnográfico es el que primero se percibe por su carácter material pero sabemos que existe una idea que lo genera que es intangible y una persona o sujeto que lo ideó, creó y utilizó.

Los objetos, las ideas que éstos proporcionan sobre los aspectos intangibles y las personas que los crearon y utilizaron merecen ser igualmente musealizadas pues aportan información valiosa y fiable de la realidad. Son objetos que están humanamente concebidos, que cubren necesidades materiales e inmateriales concretas sin pretensión de convertirse en obras de arte, y que evocan la intrahistoria y la microhistoria de la humanidad.

Lo ideal sería concebir estos centros museísticos aunando la museología del objeto y la museología de la idea que en palabras de Francisca Hernández se diferencian en que "si la museología del objeto viene definida y valorada en relación a los objetos que contiene, cuya exposición suele ir 
acompañada de una pequeña identificación y de una información muy elemental que hace posible su interpretación y el goce de su contemplación, la museología de la idea, por el contrario, hace hincapié en su función divulgativa del patrimonio como una posible oferta cultural frente a otras muchas que se le presentan al visitante" (Hernández 1998: 198).

En general, "Todos sabemos que los museos exponen objetos materiales y que ésta es su característica esencial y peculiar. (...) La cultura material está constituida por los objetos, por cualquier objeto al que suponemos portador de una información en sí mismo. Este hecho le da valor de documento con unas características determinadas. De la materia de que esté hecho, de su forma, de su decoración, podemos deducir el uso que tuvo en su momento ya fuera doméstico o ritual, militar o funerario, etc. Al ser el objeto de respuesta a la necesidad, sea ésta del orden que sea, económica, técnica, social, política, religiosa, estética..., que va a decidir sus características materiales, podemos partir de estas para deducir las necesidades que satisfizo" (García 1988: 7). Partiendo de la dicotomía ¿los objetos son museables porque están en los museos o están en los museos porque son objetos museables?, es interesante la siguiente reflexión:

"Objetos obsoletos que colocados en un determinado contexto nos marcan los hitos de desarrollo humano. ¿Qué otra cosa es un museo? Da igual que los objetos sean elementos de tecnología doméstica o pinturas; ambos nos descubren la esencia de nuestra especie: la evolución del conocimiento" (Santacana y Hernández 2006: 67).

\section{La conservación en los museos}

Teniendo en cuenta las definiciones funcionalistas de los museos, la primera función del museo es coleccionar y conservar objetos, la segunda es la exhibición de las piezas y la tercera es procurar una proyección sociocultural.

Durante demasiados años, los espacios museísticos se han ido creando en función de las tareas a las que estaban destinados, de modo que, hasta ahora, la museología había analizado el museo como un conjunto de funciones que se llevan a cabo en espacios especializados, es decir: la función de conservación se llevaba a cabo en un espacio dedicado a la misma; la de exposición, en la sala de exposiciones; la de investigación, en el espacio de investigación; etc. La zonificación espacial se creaba a través de espacios dedicados a las diferentes funciones que se desarrollan dentro de los museos (exposición, conservación, restauración, investigación, divulgación, educación, ocio, etc.). Sin embargo esta identificación entre espacio museal y función teórica no siempre se corresponde con la realidad.

A partir del siglo XXI, se entiende que el museo se divide en áreas donde se llevan a cabo diversas actividades relacionadas con diferentes funciones; por ello sus características ya no responden a necesidades funcionales, sino a los procesos museológicos concretos que se desarrollan en cada una y a la presencia o no en las mismas de piezas o público. Actualmente, la idea de que a cada función museológica corresponde un espacio funcional concreto ha sido superada. Aunque en la mayoría de las clasificaciones está implícita la idea de que cada función museológica se debe corresponder con un espacio arquitectónico concreto, teóricamente, en la actualidad, las zonas del museo se dividen -según la accesibilidad del público y la presencia o no de las piezas en cada espacio- en cuatro áreas: área de público (sólo público), área semipública (piezas y público), área privada (no público, no piezas) y área de semiprivada (piezas, no público). 
En suma, las áreas espaciales de los museos se suelen dividir en función de dos criterios: los procesos museológicos que tienen lugar en cada una de ellas (espacio funcional-función teórico/práctica) y la presencia de visitantes o de piezas en las mismas (espacio sujeto-objetual). Ambas posturas museológicas no tienen porqué ser contrarias ni contrapuestas. De hecho, la conjunción entre dichos criterios museológicos (espacio-funcional y sujeto-objetual) es posible y factible.

Sin duda, la conservación del patrimonio en los museos se lleva a cabo en todos los espacios sean públicos o privados. Ahora bien, dependiendo de las características de las piezas así como de la existencia y afluencia o no de los visitantes los parámetros de conservación varían para ajustarse a las características propias del espacio en el que se ubican (existen diferencias notables entre las medidas de conservación llevadas a cabo en las salas de exposición, en los almacenes, en las salas de cuarentena...). Es más, dentro de los museos, los espacios con colección requieren unas condiciones técnicas especiales que no tienen que mantenerse en los espacios sin colección.

Dentro de los espacios con colección la conservación del patrimonio etnográfico en los espacios no expositivos, como los almacenes o las salas de cuarentena, es más fácil que en los espacios expositivos por dos razones: en los primeros las visitas son restringidas y/o inexistentes y sólo suele estar el personal del museo y, además, se pueden colocar las piezas por familias y materiales. Este último hecho dificulta la conservación en las salas expositivas ya que los parámetros de iluminación, temperatura y humedad difieren dependiendo del tipo de piezas y de los materiales de las mismas: cerámica, textil, madera, cuero, metal, corcho, etc.

En cuanto al patrimonio etnográfico inmaterial, una de las medidas de conservación llevada a cabo en el ámbito museístico es la digitalización de soportes ya obsoletos realizada con el fin de garantizar la supervivencia de los contenidos y paliar el seguro deterioro de una copia en soporte magnético ante su uso o el paso del tiempo. La digitalización se suele completar almacenando los contenidos en soportes ópticos y conservando las copias en distintos medios como discos duros externos o los servidores de los museos.

Precisamente la principal diferencia que existe entre una colección museográfica y un museo es la funcionalidad, pues la colección museográfica se centra en la recopilación, la conservación y la exhibición, mientras que el museo además de reunir, conservar y exponer se ocupa de tres pilares básicos de la nueva museología: ordenar y clasificar, documentar e investigar, y difundir y enseñar. El museo se concibe como un centro cultural multidisciplinar y multifuncional (conservación, restauración, documentación, catalogación, exhibición, educación, divulgación e investigación).

Dentro de los museos suelen existir diferentes departamentos encargados de cada una de las funciones. Generalmente, la tarea innata del departamento de conservación es la salvaguarda y el control del estado de conservación de las colecciones del museo.

Indudablemente, la prevención es la mejor conservación y lo esencial es lograr un equilibrio entre la conservación de las piezas y su exhibición teniendo en cuenta que el mayor peligro se produce en los diferentes momentos de manipulación de las mismas. Desde mediados del XX existen unos estándares en conservación preventiva que han permitido la unificación de criterios y han favorecido el préstamo de las obras. En relación a la temperatura y la humedad relativa, los valores indicados son: de 19 a $24^{\circ} \mathrm{C}$ de temperatura y alrededor de $55 \%$ de humedad relativa. En cuanto a la iluminación, los niveles de luz en función de las obras deben oscilar entre 50 y 300 lux. 
En el museo se tienen en cuenta una serie de factores que influyen en la conservación como: temperatura, iluminación y humedad. Para una correcta conservación se deben evitar: una humedad relativa demasiado alta, demasiado baja o cambiante y una temperatura demasiado alta o cambiante. Dentro de la iluminación se debe tener en cuenta: la limitación de la iluminancia, la eliminación de la radiación ultravioleta y la limitación del tiempo de exposición. En cuanto a la contaminación los factores fundamentales son: la contaminación exterior, la contaminación interior, los contaminantes intrínsecos a las obras y el polvo.

A esto se suma la elección de los soportes empleados para exponer y almacenar las piezas que deben procurar la conservación óptima de las mismas. Los sistemas expositivos (vitrinas contenedoras, muros expositores, tarimas, peanas...) no sólo articulan los espacios favoreciendo el discurso museológico y la circulación del público, sino que también deben respetar y favorecer la conservación de las diferentes piezas. En el caso de los almacenes, a la hora de diseñar y elegir las unidades de mobiliario y los contenedores de almacenamiento se debe tener en cuenta las características de las piezas tales como medidas, formatos y materiales. Por ejemplo, el uso de estanterías abiertas regulables de metal, de distintas anchuras y alturas, con baldas que se fijan en bastidores de metal perforados es muy útil para una colección etnográfica, compuesta de materiales varios; siempre y cuando el almacén sea hermético, esté climatizado y cuente con sistemas de ventilación artificial filtrada que proteja a las piezas del polvo. Junto a esto, el sistema de almacenaje móvil es muy eficaz, útil y rentable ya que permite multiplicar el espacio en caso de crecimiento y tiene numerosas ventajas como: la necesidad de un solo pasillo para deambular, el aprovechamiento del espacio, el cerramiento compacto y hermético, o la existencia de una amplia gama de posibilidades en el diseño interior de las unidades -estantes, soportes cilíndricos sobre guías deslizantes, cajones de diversas alturas con o sin fondo, e incluso plataformas para grandes formatos-.

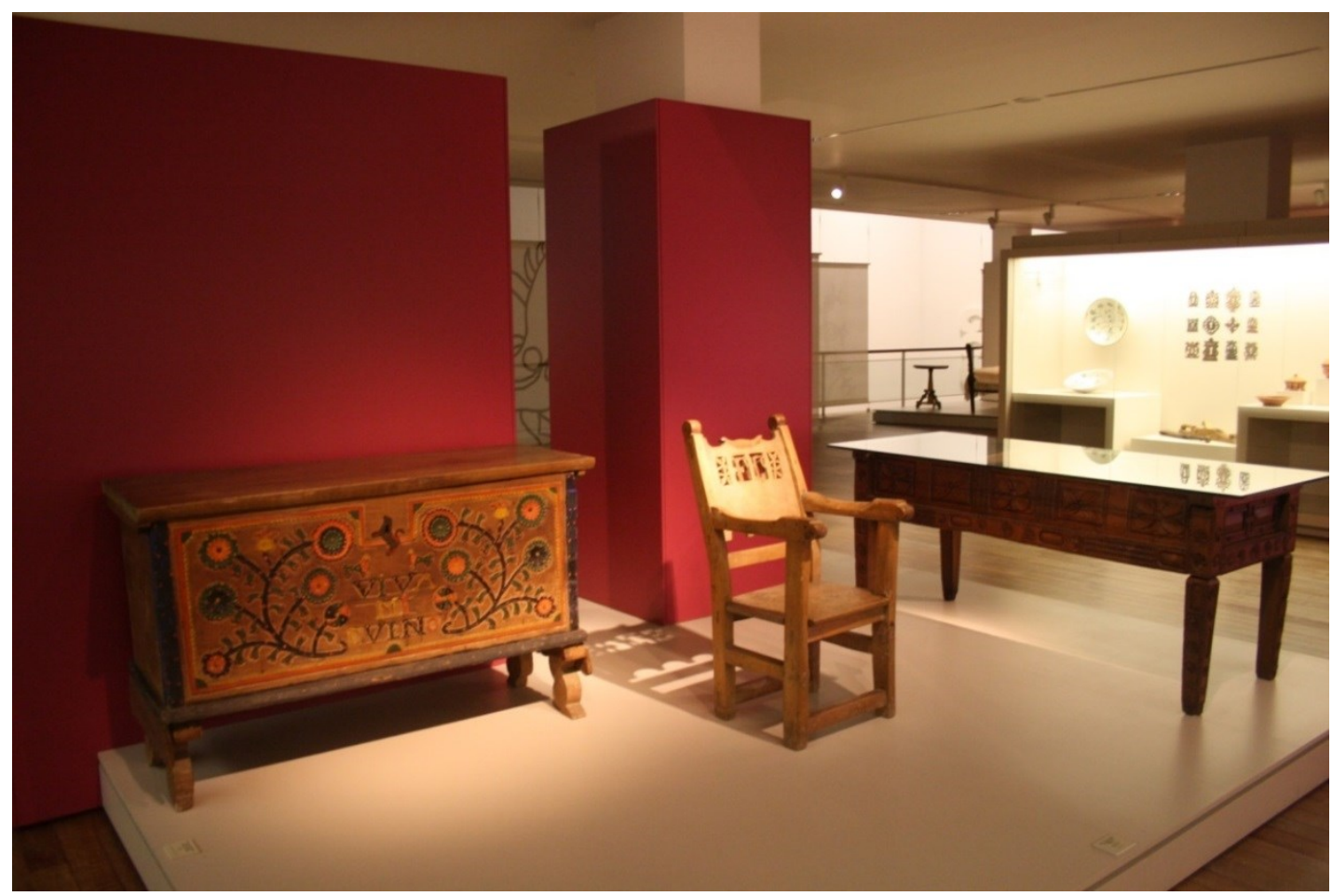

Figura 1: Sala de exposición del Museo Etnográfico de Castilla y León. @Blanca Flor Herrero Morán. 


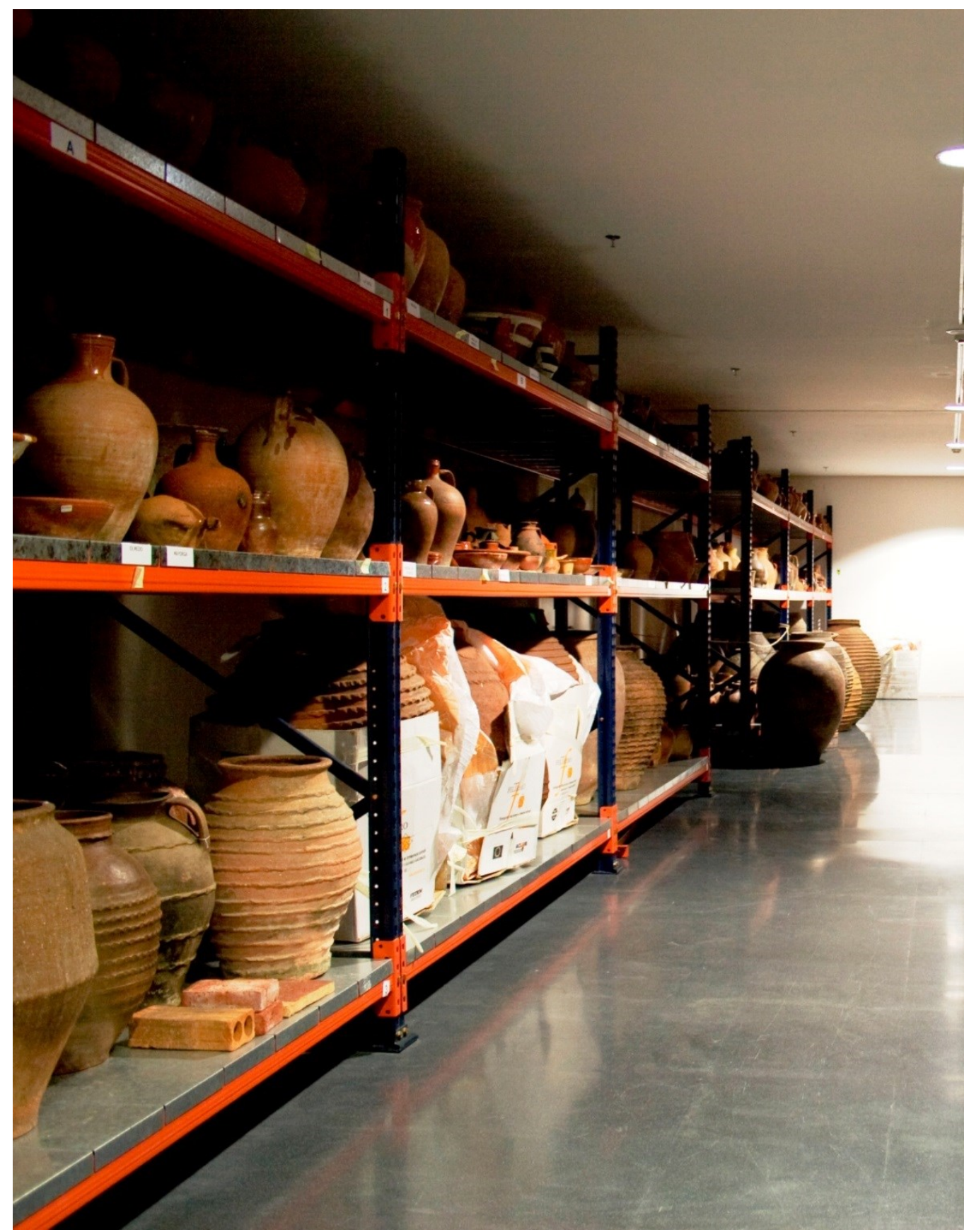

Figura 2: Almacén del Museo Etnográfico de Castilla y León. @Blanca Flor Herrero Morán.

El mantenimiento de cualquier tipo de patrimonio plantea unas dificultades que nacen tanto de su propia naturaleza, como de la falta de su conocimiento y de la inexistencia de instrumentos legales, económicos y sociales que permitan su conservación y rehabilitación. Este hecho se magnifica en el caso del patrimonio etnográfico pues los estudios o inventarios existentes sobre dicho patrimonio son insuficientes y la desaparición de los modos de vida y del patrimonio que testimonia los mismos les hacen especialmente vulnerables. A su vez dado que el patrimonio etnográfico cuenta con bienes materiales e inmateriales su conservación es realmente compleja pues el patrimonio tangible por su carácter material se conserva más fácilmente que el intangible. 
Tabla 1: Esquema: La conservación del patrimonio etnográfico a través de la musealización

\begin{tabular}{|c|c|}
\hline & LA CONSERVACIÓN DEL PATRIMONIO ETNOGRÁFICO A TRAVÉS DE LA MUSEALIZACIÓN \\
\hline \multicolumn{2}{|c|}{ Proceso de conservación del patrimonio etnográfico } \\
\hline \multicolumn{2}{|r|}{ Recelo por el progreso: se conserva el patrimonio etnográfico } \\
\hline \multicolumn{2}{|r|}{ - $\quad$ Admiración por el progreso: se permuta el patrimonio etnográfico por objetos nuevos o por dinero } \\
\hline- & $\begin{array}{l}\text { Valoración del patrimonio etnográfico (estética, histórica y cultural): se conserva, se colecciona y se } \\
\text { musealiza el patrimonio etnográfico }\end{array}$ \\
\hline \multicolumn{2}{|c|}{ Proceso de musealización del patrimonio etnográfico } \\
\hline \multicolumn{2}{|r|}{ - El patrimonio etnográfico se conserva ante el riesgo de desaparición } \\
\hline \multicolumn{2}{|r|}{ - $\quad$ El patrimonio etnográfico es considerado un bien museable } \\
\hline & $\begin{array}{l}\text { La principal dificultad es distinguir las piezas con valor etnográfico que deben ser musealizadas y crear } \\
\text { instituciones que sean auténticos museos }\end{array}$ \\
\hline \multicolumn{2}{|c|}{ Museos etnográficos: objeto, no objeto y sujeto } \\
\hline \multicolumn{2}{|c|}{ - Se pasa del objeto de museo al objeto del museo } \\
\hline \multicolumn{2}{|r|}{ - El patrimonio etnográfico material e inmaterial tiene un valor colectivo que está por encima del individual } \\
\hline- & $\begin{array}{l}\text { Los museos etnográficos deben aunar la museología del objeto y de la idea y conservar el objeto, el no } \\
\text { objeto y el sujeto }\end{array}$ \\
\hline \multicolumn{2}{|c|}{ La conservación en los museos } \\
\hline \multicolumn{2}{|r|}{ - Los criterios museológicos espacio-función y objeto-sujeto son perfectamente compatibles } \\
\hline \multicolumn{2}{|r|}{ - $\quad$ La conservación del patrimonio en los museos se lleva a cabo en todos los espacios } \\
\hline- & $\begin{array}{l}\text { La conservación del patrimonio etnográfico en los museos es compleja por la conjunción existente en } \\
\text { bienes tangibles e intangibles. }\end{array}$ \\
\hline
\end{tabular}


Otra dificultad añadida dentro de la conservación del patrimonio etnográfico son los bienes inmuebles por ser obras que ocupan un determinado espacio y que no pueden ser trasladadas de un lugar a otro, ya sea porque son estructuras (edificaciones), o porque están en inseparable relación con el terreno (sitios arqueológicos). Se trata de bienes que no se pueden introducir en un museo y que debido a la falta de protección y conservación están desapareciendo a un ritmo vertiginoso.

Dado que las piezas etnográficas son bienes heredados y legados de los antepasados debemos potenciar la conservación del patrimonio etnográfico y reflexionar sobre los diferentes modelos que permiten dicha acción entre los que destaca la musealización a través de la puesta en marcha y funcionamiento de los museos etnográficos.

\section{Bibliografía}

ALONSO, J. L. (2002). "Los objetos al servicio del hombre. Enseres". En Catálogo de la Exposición Enseres del Museo Etnográfico de Castilla y León. Zamora: Museo Etnográfico de Castilla y León, 154-159.

DÍAZ, I. (2008). La memoria fragmentada. El museo y sus paradojas. Gijón: Trea.

DÍAZ, J. (1992). La memoria permanente. Reflexiones sobre la tradición. Salamanca: Ámbito.

FERNÁNDEZ, J. (1996). Introducción a la conservación del patrimonio y técnicas artísticas. Barcelona: Ariel.

FONTAL, O. (2003). La educación patrimonial. Teoría y práctica en el aula, el museo e Internet. Gijón: Trea.

GARCíA, Á. (1988). Didáctica del museo: el descubrimiento de los objetos. Madrid: Ediciones de la Torre.

GARCÍA, M. P. (2009). Humilde condición. El patrimonio cultural y la conservación de su autenticidad. Gijón: Trea.

GOMBRICH, E. H. $(2003,1950)$. Historia del arte. Madrid: Random House Mondadori.

-(2004, 1969). Breve Historia de la Cultura. Barcelona: Península.

GONZÁLEZ-VARAS, I. (2006). Conservación de Bienes Culturales. Teoría, Historia, Principios y Normas. Madrid: Cátedra.

HERNÁNDEZ, F. (1998). El museo como espacio de comunicación. Gijón: Trea.

-(2002). El patrimonio cultural: la memoria recuperada. Gijón: Trea.

MACARRÓN, A. M. (2008). Conservación del Patrimonio Cultural. Criterios y normativas. Madrid: Síntesis.

MARCOS, J. (2008). Objetos, sujetos e ideas (Bienes etnológicos y memoria social). Badajoz: Diputación de Badajoz.

PANOFSKY, E. $(1985,1955)$. El significado de las artes visuales. Madrid: Alianza.

RODRÍGUEZ, S. (1992). "Conservación y divulgación del patrimonio etnográfico. El papel de los museos". En Actas do I Congreso Internacional de Cultura Galega, Vigo: Consellería de Cultura e Xuventude. Xunta de Galicia, 313-325.

SANTACANA, J. y HERNÁNDEZ, F. X. (2006). Museología crítica. Gijón: Trea.

WATTENBERG, E. (1995). "Patrimonio Cultural de Castilla y León". En Historia de una cultura. Castilla y León en la Historia de España. Valladolid: Junta de Castilla y León. Consejería de Cultura y Turismo, 479-568. 


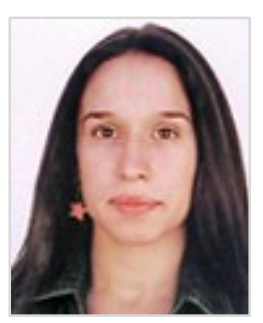

\section{Blanca Flor Herrero Morán}

blancaflorhm@hotmail.com

Doctora en Historia del Arte con la tesis titulada: "El Museo Etnográfico de Castilla y León: patrimonialización y musealización", y Licenciada en Historia del Arte por la Universidad de Salamanca. Actualmente es coordinadora de varios grupos de trabajo sobre el patrimonio etnográfico de Castilla y León en el CFIE de Zamora, y profesora de enseñanza secundaria de la especialidad de geografía e historia en Castilla y León. Ha obtenido la beca del Ministerio de Educación y Ciencia "Recuperación y Utilización Educativa de Pueblos Abandonados" en Granadilla (Cáceres), y la beca de colaboración para Licenciados en Historia del Arte con el Gabinete de Comunicación y Protocolo de la Universidad de Salamanca. Tambien obtuvo una beca de formación del personal investigador (FPI) con la Universidad Salamanca. Junta de Castilla y León, y otra beca de Investigación de la Fundación Villalar de Castilla y León para el trabajo: El Museo Etnográfico de Castilla y León: una seña de identidad".

Artículo enviado el 06/08/2013

Artículo aceptado el 26/11/2013 